\title{
As determinações da prática discursiva da escrita
}

Freda Indursky*

\section{Resumo}

O presente artigo propõe uma reflexão sobre a prática discursiva da escrita à luz do dispositivo teórico da análise do discurso, levando em consideração que a escrita, neste quadro teórico, é a prática de um sujeito atravessado pelo inconsciente e afetado pela ideologia, por um lado, e, por outro, ela se produz com base na retomada de saberes inscritos no interdiscurso pelo trabalho entrecruzado da interpretação, da memória e do esquecimento. Essa é a moldura teórica que estabelece as condições para levantar e examinar os elementos que determinam essa prática discursiva.

Palavras-chave: Determinações históricas e sociais. Interpretação. Língua. Memória e esquecimento. Materialidade linguístico-discursiva.
Escrever implica repetição que pode ser entendida como um retorno ao mesmo, mas pelo fato de aparecer em outro lugar e em outro momento, torna-se uma prática única.

(SCHONS, 2005)

\section{Produzindo um efeito-início ${ }^{1}$}

O presente trabalho inscreve-se em um dossiê da revista Desenredo da Universidade de Passo Fundo, organizado por Evandra Grigoletto, da Universidade Federal de Pernambuco, e Márcia Helena S. Barbosa, da Universidade de Passo Fundo, com o objetivo de prestar homenagem a Carme Regina Schons, a querida professora Carme da Universidade de Passo Fundo, que recentemente nos deixou. Em função disso, reli alguns textos de Carme e voltei a me emocionar,

Doutora em Estudos da Linguagem, Professora Titular, atua como professora convidada do Programa de Pós-Graduação em Letras da Universidade Federal do Rio Grande do Sul. E-mail: freda.indursky@gmail.com

Data de submissão: mar. 2016 - Data de aceite: maio 2016 http://dx.doi.org/10.5335/rdes.v12i1.5954 
antes de mais nada, pela paixão com que ela se dedicava à escrita de seus textos, fossem eles da ordem do político ou da linguagem. Diante desses dois eixos - 0 político e a linguagem -, que também atravessam meu próprio trabalho, decidi-me, quase sem me dar conta, a colocar meu foco sobre uma questão essencial da linguagem: a escrita.

O que teria me dirigido nessa direção, logo de início, não estava claro para mim. Mas, à medida que fui escrevendo, fui dando-me conta de que este artigo, de fato, e antes de mais nada, reúne em si, tanto o político como o linguageiro, como veremos a seguir. E, certamente, inscreve-se na temática deste número da revista Desenredo, dedicado à reflexão sobre subjetividade e alteridade, tema que diz muito de perto à análise do discurso, quadro teórico em que me inscrevo como professora e pesquisadora. E, no mesmo movimento, estarei abordando os caminhos trilhados por Carme, pois seus escritos estarão no horizonte de minha reflexão.

\section{Apresentando as trilhas}

Nunca esgotamos de nos inscrever. (SCHONS, 2005)

Exponho, a seguir, os propósitos do presente artigo. Nele pretendo deter-me sobre uma prática específica do sujeito - a escrita - e sua relação com a exterioridade. Muito já se escreveu, e eu mesma já percorri mais de uma vez essas trilhas, mas, como diz Carme Schons:
[...] quando escrevemos, estamos sempre fazendo rascunhos em nossas vidas, os quais se cruzam com tantas outras vidas rascunhadas e (re)desenhadas e a nossa escrita implica escolhas, talvez diferentes daquelas que já estão legitimadas (2005, p. 139).

Tomo essa citação como mote para apontar os caminhos que vou percorrer na produção deste artigo. Certamente vou tangenciar questões já tratadas em textos anteriores, desfazendo a ilusão de estabilidade dos sentidos que a função discursiva do "ponto final" lhes conferiu.

Em artigo anterior, afirmei que um texto é uma unidade provisoriamente estruturada que pode ser desestruturada a qualquer momento sob o efeito do trabalho de leitura de um sujeito leitor (INDURSKY, 2001). Volto, agora, a essa questão, mas, no presente artigo, não é sobre o trabalho de leitura realizado por um sujeito-leitor outro que vou lançar meu olhar. O que me move agora com esta retomada é a possibilidade que o sujeito-autor tem de ocupar o lugar discursivo do outro, do leitor, retornando a seu próprio texto para sobre ele fazer uma leitura desestabilizadora de seu efeito de completude, seja para se autocorrigir, seja para trazer outros fios discursivos que, por diversos motivos, não puderam ser contemplados anteriormente e tramá-los àqueles que aí já se encontravam. Sobre esse fazer, trago de Orlandi o entendimento de que "a incompletude não deve ser pensada em relação a algo que seria (ou não) inteiro, mas antes em relação a algo que não se fecha" (1996, p. 11). 
Parto dessa reflexão sobre incompletude para pensar a escrita. Ela permite-me distinguir escrita de texto. Este apresenta começo, meio e fim. Já a escrita, ao contrário, não é um produto acabado, mas um processo. À luz da análise do discurso, ${ }^{2}$ pode-se entender um processo como algo em movimento, que não se fecha. Ele pode ser suspenso, pode ser pausado, pode ser interrompido, mas não tem um fim. Pensar a escrita como processo implica dizer que ela pode sempre ser retomada e receber continuidade. Trata-se de um processo que o ponto final não pode deter, ao contrário do que ocorre com o ponto final de um texto, que marca simbolicamente seu término.

Ao proceder à retomada de seus escritos, o sujeito-autor transforma-os em rascunho(s) de novo(s) texto(s). Não estou aqui me referindo a um texto que ainda se encontra sob a guarda do sujeito-autor, no aconchego protegido de seu arquivo, pois, nesse caso, o efeito de estabilização dos sentidos ainda não ocorreu e, por conseguinte, o autor poderá voltar a seu texto quantas vezes quiser, antes de lhe apor o ponto final que vai produzir o efeito de completude e de estabilização dos sentidos. Ao contrário. Refiro-me a um texto que já foi publicado, fato que está na origem da ilusão de que tudo o que precisava ser dito nele se encontra.

O ponto final, em textos publicados, produz um efeito de fronteira, que separa ilusoriamente o texto do que ficou fora de seus limites internos, produzindo um corte entre o texto e o interdiscurso, estancando-lhe o fluxo. O que procuro examinar no presente artigo vai justamente em direção contrária a esse efeito de fronteira. $\mathrm{O}$ que estou propondo é a desconstrução dessa ilusão que separa o externo do interno; que trabalha em um tempo diferente, o tempo da reflexão e da elaboração teórica e não o tempo objetivo da produção acadêmica, para a qual não apenas o tempo é um fator determinante, mas também o espaço medido em número de páginas, palavras ou caracteres.

Para dar continuidade à escrita de um texto já publicado, o sujeito-autor precisa desestabilizar a função discursiva do ponto final, devolvendo-o ao fluxo do interdiscurso e ao processo de escrita. A questão teórica inicial que o presente artigo coloca é o estabelecimento de uma distinção entre texto (enquanto produto) e escrita (enquanto processo): efeito de fechamento e completude versus efeito de abertura e incompletude.

Esse é um trabalho discursivo que pode ser produzido em diferentes situações. Um primeiro caso, e o mais simples de todos, é, por exemplo, o de um texto esgotado que, antes de sua nova publicação, o autor revisa-o e o republica como uma edição revista e aumentada. Mesmo que o sujeito-autor não realize grandes alterações, o referido texto voltou a ser aberto, voltou a ser rascunhado, e seus sentidos puderam ser desestabilizados e alterados antes de sua nova publicação. ${ }^{3}$

Mas esse não é o único caso em que um texto pode voltar ao estatuto de rascunho. Há várias situações em que 
isso pode ocorrer. Dentre elas, podemos pensar no trabalho didático de sala de aula ou, ainda, no trabalho acadêmico, que retornam ao processo de escrita, ambos sob a determinação de um professor.

Penso que esse processo ocorre também no trabalho literário, e, nesse campo, destaco, como exemplo, Borges. Em determinado momento de sua vida, seus editores se deram conta que ele tinha um número considerável de contos dispersos em diferentes revistas literárias. Pediram-lhe então que fizesse uma seleção, para reuni-los em um livro. Borges aceitou a tarefa e quando finalmente encaminhou seus contos, os editores constataram que Borges não havia feito uma revisão, mas os havia reescrito inteiramente. Estavam diante de uma coletânea de textos originais. $\mathrm{Ou}$ seja: Borges tomou seus textos, abriu-os, fez deles rascunhos, desestabilizou sua provisória estruturação e seus efeitos de sentido, reescrevendo-os novamente, antes de produzir o efeito de estabilização dos sentidos que decorre do efeito-fecho (GALLO, [1994] 2008), ${ }^{4}$ a partir da aposição de um ponto final (ORLANDI, 2001). A esse propósito, cito Orlandi:

[...] um mesmo texto volta sempre, fazendo seu retorno em várias retomadas por um sujeito autor que trabalha diferentes formulações (versões) em uma história inacabada de diferentes textualizações possíveis (2001, p. 96).

Pesquisadores, por sua vez, também retomam seus escritos e voltam a abri-los e devolvê-los à categoria de rascunhos para produzir novos textos, pois, como afirma Orlandi, "o dizer não tem começo verificável: o sentido está (sempre) em curso" (1996, p. 11). Diria que é nesse último caso que enquadro o presente artigo. Vou retomar algumas questões desenvolvidas em meus trabalhos sobre leitura e escrita, transformá-las em rascunhos para poder agregar novos fios discursivos a serem tramados aos anteriores, pois, como afirma Schons,

[...] o fato de desconfiarmos de nosso primeiro rascunho e inventarmos sempre outro, a partir daquele que já fora refeito, implica esforços heterogêneos e, ao mesmo tempo, únicos (2005, p. 146).

Desse modo, o que estará em jogo na prática discursiva da escrita são dois aspectos da exterioridade. Por um lado, rascunhar sobre os próprios textos pode ser visto pelo viés da intertextualidade, modalidade própria da escrita acadêmica e que, no presente artigo, consistirá em dialogar com textos de Pêcheux, Courtine e Orlandi. E, por outro lado, esse processo de rascunhar pode conduzir o texto ao interdiscurso, que funciona como "preenchimento do formulável", como diz Courtine ([1983] 1999). Ou seja: essa nova abertura ao interdiscurso vai devolver o texto à incompletude e o sujeito-autor à busca ilusória de completude.

As novas versões de um texto colocam o sujeito-autor frente à inexorabilidade da incompletude, visto que, em toda escrita, há lacunas e esquecimentos e "a falta é o lugar do possível na linguagem. É isso que chamamos a abertura do simbólico" (ORLANDI, 2001, p. 19). 
Essas diferentes versões jogam com a ilusão do sujeito-autor em busca de preencher as "brechas" e, desse modo, encontrar a tão desejada completude, bem como controlar os sentidos que estão em movimento e que, em função disso, insistem em lhe escapar. Habitualmente, associamos a movimentação dos sentidos ao processo discursivo de leitura de um sujeito-leitor, o outro com quem o sujeito-autor estabelece uma interlocução discursiva. Mas o que trago aqui, neste trabalho, é a movimentação dos sentidos realizada pelo próprio sujeito-autor a partir da leitura de um texto por ele produzido. Trata-se da necessária ilusão de que, com a nova versão, tudo o que ainda não havia sido dito finalmente será formulado. Essa é a grande ilusão do sujeito-autor ao voltar à escrita de textos seus. Seu texto é uma formulação dentre as diversas outras que poderia ter produzido, razão pela qual retorna ao processo de escrita, em busca da formulação ideal que deixou de fazer.

Trata-se de um movimento incontornável do sujeito ao formular uma nova versão de um texto. É em Orlandi, ainda, que nos apoiamos para pensar essa questão:

Ao longo de toda uma vida não é talvez senão o mesmo texto que trabalhamos incessantemente, acrescentando, transformando, repetindo, à busca de uma forma mais acabada (2001, p. 95-96).

Explicitados todos esses elementos que fazem parte das condições de produção da escrita do presente artigo, voltemos ao que já afirmei anteriormente, nessa mesma seção. No presente trabalho, pretendo retornar a alguns de meus textos para refletir especificamente sobre a prática discursiva da escrita. Já me ocupei dessa prática isoladamente ou em justaposição com a prática da leitura. Retorno com frequência às práticas discursivas do sujeito como se fossem um caleidoscópio: o movimento giratório, a cada vez, revela novas formas, novas configurações, novas combinações de cores. E não consigo resistir ao apelo de meu imaginário caleidoscópio. O caso específico que aqui trago consiste em tornar-me leitora de meus próprios textos, transformar em rascunho algumas de suas passagens para a produção de um novo texto com o propósito específico de refletir sobre a prática discursiva da escrita e os elementos que a determinam. Essa é a questão que me move a retomar meus textos e voltar a rascunhá-los.

Contudo, cabe aqui um esclarecimento: este texto não se propõe a refletir sobre A escrita da análise do discurso. Esse é o título de um capítulo do livro Discurso e texto, de Eni Orlandi (2001, p. 31-57). Meu propósito aqui é refletir sobre a escrita à luz da teoria da análise do discurso. Tomo a escrita porque ela promove a textualização de diferentes discursividades, ou seja, por seu viés, dá-se a materialização do interdiscurso. Com isso, não pretendo que a escrita seja a única via para a materialização do discurso, mas, certamente, ela é uma das formas de fazê-lo. E, também, faz-se mister lembrar que ela é uma das fun- 
ções discursivas do sujeito, por meio da qual podemos capturar marcas de sua subjetividade, e é por meio dela que se dá entrada no simbólico da discursividade em circulação.

Da mesma forma que é possível refletir teoricamente sobre leitura e sobre texto, julgo importante fazer uma reflexão teórica sobre a escrita como prática discursiva do sujeito. Nesse ponto, faz-se necessário outro reparo: tampouco pretendo voltar a refletir sobre a noção de texto propriamente dito, mas sobre a prática da escrita que lhe subjaz, pois entendo, como já explicitei, que escrita não se confunde com texto, embora sejam noções muito próximas. No presente artigo, meu foco vai incidir sobre a prática discursiva da escrita à luz da teoria da análise do discurso.

Ao pensar sobre a prática da escrita, que está relacionada a uma das funções discursivas do sujeito, não há como deixar de fazer referência ao sujeito em sua função de autoria. Isso vai ocorrer em determinados momentos deste artigo, entretanto, o foco deste trabalho também não é o sujeito, mas sua prática discursiva de escrita propriamente dita.

Apresentadas as trilhas, passemos, então, a percorrê-las.

\section{As determinações da escrita}

\author{
O que é a escrita?
}

\begin{abstract}
A escrita como "novidade" é apenas efeito do trabalho de interpretação e de memória, visto que o que dizemos reaparece e sempre retorna em outro lugar.
\end{abstract}

(SCHONS, 2005)

A escrita é um dos modos de que o sujeito lança mão para relacionar-se com a história, com seu tempo, com a sociedade, em suma, para inscrever-se no corpo social. E, é por meio desse fazer do sujeito que sua escrita inscreve-se também na memória social.

A escrita consiste em um trabalho de tramar fios discursivos provenientes do intertexto e/ou do interdiscurso. Em função disso, podemos entender que da escrita resulta um texto que é tecido de citações - relações com o intertexto de glosas, de paráfrases discursivas e fragmentos discursivos que, em outro trabalho, designei de incisas discursivas (INDURSKY, [1997] 2013), modalidades que estabelecem diferentes modos de se relacionar com o interdiscurso. Vale dizer: a escrita consiste em um tecer e retecer de fragmentos de discursos outros. Ela trabalha com o simbólico e produz um espaço simbólico, em que diferentes vozes anônimas (ou não) ecoam, se entrelaçam e, mesmo, por vezes, se contradizem. 
Uma textualidade assim realizada é resultado do trabalho discursivo produzido por um sujeito que supõe estar na origem de seu dizer. Essa crença ocorre porque o sujeito é afetado pelo inconsciente e interpelado pela ideologia. Desse modo, o sujeito do discurso pensa que seu dizer tem origem nele mesmo quando, de fato, os fios discursivos que mobiliza para tecer seu texto procedem da exterioridade. Dito diferentemente: a escrita, ao incorporar a exterioridade, torna-a constitutiva do texto.

Pêcheux já nos alertava que, em função da dupla determinação do sujeito - pelo inconsciente e pela ideologia -, a autonomia da língua com que o sujeito do discurso se identifica e produz discursividade é relativa. Penso que isso se aplica à escrita também, pois ela é a prática de um sujeito assim constituído, de modo que essa prática consiste em um processo de produção que dá materialidade linguística a saberes dessintagmatizados/ desnivelados provenientes do interdiscurso. E mais: no mesmo movimento em que se dá essa interiorização, esses fios discursivos são sintagmatizados/nivelados pelo trabalho discursivo do sujeito do qual resulta o apagamento das marcas da interdiscursividade/exterioridade. Esse é o efeito que a prática discursiva da escrita persegue: apagar os vestígios da exterioridade no interior do texto. $\mathrm{E}$ é esse trabalho discursivo da escrita que inscreve o sujeito ao mesmo tempo nas redes discursivas de memória e na função autoral (INDURSKY, 2001, 2009).
Mas observemos mais de perto nosso objeto de reflexão, a escrita.

\section{A escrita como prática social e política}

\author{
O texto corporifica o encontro entre \\ sujeito, sentido e história.
}

(SCHONS, 2005)

Ao entender a escrita como acabamos de apresentá-la, podemos afirmar que toda escrita é resultante de um processo de reescrita de fios discursivos provenientes de um discurso-outro, inscrito no interdiscurso. Conforme nos ensina Pêcheux,

[...] os elementos do interdiscurso [...] que constituem, no discurso do sujeito, os traços daquilo que o determina, são re-inscritos no discurso do próprio sujeito ([1975] 1988, p. 163, grifo do autor).

Dito de outra forma: a escrita de um texto dá corpo e materialidade a saberes que já estão em circulação, inscritos tanto do interdiscurso quanto na memória discursiva de formações discursivas.

Conceber a escrita dessa forma consiste, pois, em pensá-la como uma prática social, determinada pelo interdiscurso que representa a memória do dizer: tudo que já foi produzido lá se encontra. E o resultado dessa prática discursiva da escrita vai necessariamente retornar ao interdiscurso que é a memória do dizer. É em função desse ciclo interdiscurso escrita - interdiscurso que a escrita pode ser entendida como uma prática social. Ou, como afirma Orlandi, "A escrita é 
uma forma de inscrever o sujeito na ordem social" (2012, p. 169).

Com base no que precede, entendo que a escrita, além de ser uma prática social, também é uma prática política, pois o sujeito-autor é um sujeito interpelado pela ideologia e seu trabalho discursivo de escrita dá-se à luz de sua determinação ideológica. O político, por conseguinte, determina a escrita que vai carregar em si os vestígios dessa determinação.

O sujeito realiza sua prática discursiva de escrita inscrevendo-se na discursividade (interdiscurso) e na memória de uma formação discursiva (memória discursiva). Tal fato irá determinar inexoravelmente o modo como os fios discursivos provenientes do exterior irão se articular e textualizar, permitindo vislumbrar o encontro da linguagem com a ideologia, possibilitando observar como a ideologia materializa-se na escrita de um sujeito, nela imprimindo uma direção de sentidos e seus efeitos de evidência, pois, como salienta Pêcheux,

[...] toda prática discursiva está inscrita no complexo contraditório-desigual-sobredeterminado das formações discursivas que caracteriza a instância ideológica em condições históricas dadas ([1975] 1988, p. 213).

E, se toda prática discursiva inscreve-se nesse complexo, a escrita, por ser uma prática discursiva, nele também encontra sua inscrição, razão pela qual entendemos tratar-se de uma prática política. Vejamos de que modo isso ocorre.

\section{A linguagem e o processo de materialização da interpretação}

\author{
Trabalhar a linguagem, mais \\ exatamente a língua, \\ na perspectiva da Análise do Discurso \\ constitui-se num desafio e, também, \\ numa forma de resistência.
}

(SCHONS, 2006)

A prática discursiva da escrita, como vimos na seção anterior, é afetada pela história. Na presente seção, examinaremos uma outra determinação que essa prática sofre. Trata-se da língua. Mas não uma língua fechada, sem ambiguidades. A prática discursiva da escrita vai convocar uma língua sujeita a jogos e equívocos. Como afirma Orlandi:
A linguagem é um trabalho, uma prática. O que ela tem de específico é que ela é um trabalho simbólico. [...]
A prática, que é a linguagem, se relaciona com as práticas em geral. Para fazer sen- tido, a língua, sujeita a falhas (divisão), se inscreve na história, produzindo discursivi- dade (2012, p. 152, grifo da autora).

Como já foi apontado, a escrita é uma prática social, tecida de discurso, por intermédio da qual a ideologia se materializa. Acrescentemos, agora, que a escrita, por sua vez, ganha materialidade por meio da língua, razão pela qual dela vamos nos ocupar mais detidamente a seguir.

A língua, historicamente determinada, "constitui o lugar material onde se realizam os efeitos de sentido" ([1975] 1990, p. 172, grifo dos autores), como nos dizem Pêcheux e Fuchs. Ou seja, 
a língua, por meio das estruturas que lhe são próprias, dá materialidade à escrita, podendo entrar, nesse processo de textualização, em relação com o "não está" ou ainda com o "ainda não está", de que nos fala Pêcheux ([1982] 1990, p. 8). São esses traços que atribuem à língua seu estatuto de não fechamento, que vão sustentar suas transformações e seus equívocos.

De outro modo, se a língua é sujeita a falhas, como estamos vendo neste início de seção, podemos considerar que ela não é transparente. De modo que é com uma língua opaca, sujeita a jogos, deslizamentos que a escrita é produzida, sendo, em consequência disso, também ela afetada por esses traços de opacidade que determinam a língua com a qual é produzida. Em função disso, o sujeito que produz a escrita é instado a interpretar, pois "o sentido não preexiste à sua constituição nos processos discursivos" (GADET; PÊCHEUX, [1981] 2004, p. 158). O sentido decorre, assim, do trabalho de interpretação realizado por um sujeito historicamente determinado, e essa interpretação é resultante da relação que se estabelece entre a língua e a ideologia. Esse trabalho antecede a escrita propriamente dita, pois, como Orlandi sublinha:

Não há sentido sem interpretação e a interpretação é um gesto do sujeito carregado de ideologia, que torna evidente o que, na realidade se produz por complexas relações entre sujeito, língua e história (2012, p. 153).

Em outras palavras, frente a saberes em circulação, o sujeito os interpreta à luz da formação discursiva com que se identifica e é em função de sua captura ideológica que vai posicionar-se e interpretar tais saberes para poder produzir sua escrita. Ou seja: a escrita coloca o sujeito forçosamente diante da injunção de interpretar para produzir um efeito de sentido como se fosse o sentido. Vale dizer que a escrita, enquanto prática discursiva, trabalha para produzir a ilusão de sentido único.

É, pois, pelo viés da língua que seu gesto de interpretação, materializado na escrita, trará o político para a escrita e produzirá sentido. Isto é: não se trata apenas de recortar e sintagmatizar fios discursivos dispersos e provenientes do interdiscurso, mas de fazê-lo a partir de um determinado lugar discursivo afetado pela ideologia, de modo que nada garante um sentido a priori, isto é, os fios discursivos não são portadores de sentidos previamente produzidos e cristalizados, embora estejam associados a uma rede de memória, pois, dependendo do posicionamento do sujeito da escrita e de seu processo de interpretação, ele poderá entretecer tais fios, conduzindo-os em determinada direção de sentidos ou a uma outra direção que antagonize com a primeira.

Logo, é pelo trabalho sobre os sentidos, por meio da língua, feito por um sujeito ideologicamente identificado, que os fios discursivos ganharão materialidade linguístico-discursiva e produzirão um determinado efeito de sentido. Melhor dizendo: a identificação ideológica determina a interpretação que, por sua vez, 
vai determinar o jogo com a língua. Há um jogo sobredeterminado que subjaz à escrita de um sujeito e que lhe permite identificar-se ou contraidentificar-se com determinados sentidos, podendo mesmo chegar a deslocamentos importantes que serão a marca de sua resistência por meio da materialização que a língua produzirá em sua escrita.

É, pois, pelo viés de uma língua assim concebida - sujeita a falhas e ao equívoco - que a discursividade inscreve-se na escrita de um sujeito. No entanto, tais determinações históricas não garantem a estabilidade dos sentidos. Como coloca Pêcheux, "só há prática através de e sob uma ideologia" da mesma forma que "só há ideologia pelo sujeito e para os sujeitos" ([1975], 1988, p. 149). Por conseguinte, a prática da escrita é ideológica, e seu trabalho consiste em dar materialidade linguística à materialidade discursiva, que é a matéria-prima com a qual a escrita se defronta e trabalha, interpretando e dando-lhe materialidade (INDURSKY, 2009). Trata-se do trabalho dos sentidos sobre os sentidos pelo viés da interpretação e da resistência que vão se fazer presentes na prática discursiva da escrita produzida por um sujeito. Portanto, não há interpretação ingênua nem, tampouco, a escrita o é. É o gesto de interpretação que estabelece a relação entre a historicidade dos sentidos e o trabalho discursivo da escrita.

Por tudo quanto precede, percebe-se um denso imbricamento entre ideologia, interpretação e língua na prática discursiva da escrita.

\section{A prática discursiva da escrita e seu atravessamento pela cultura}

Para pensar a noção de cultura, penso ser necessário, antes, passar por outra noção, a de formação social. Não pretendo mergulhar na densa e complexa literatura que existe sobre essa noção. Mas, de qualquer forma, necessito sinalizar que são vários os caminhos teóricos para dela tratar.

Via de regra, minha abordagem dessa noção é a que encontramos nos textos marxistas, isto é, tomo-a como uma formação econômico-social que trata das relações sociais a partir dos modos de produção e de reprodução que caracterizam uma sociedade. Entretanto, para pensar a prática discursiva da escrita, entendo ser preciso repensar essa noção, tornando-a mais abrangente. Faço isso, com base nos aparelhos ideológicos de Estado formulados por Althusser, dentre os quais se encontra o aparelho ideológico cultural (ALTHUSSER, [1970] 1996). É em função desse aparelho cultural que proponho a retomada da noção de formação social, considerando-a como um sistema complexo, historicamente determinado, em que entra em jogo, além dos sistemas político e econômico, 
o sistema sociocultural de uma sociedade, de modo que a cultura passe a ser considerada, par e passo, com os demais elementos que a constituem e, em função disso, possa ser tomada como um dos elementos determinantes da prática discursiva da escrita.

Cabe, pois, formular uma noção discursiva de cultura, mesmo que tomada em sua provisoriedade, e relacioná-la às noções do dispositivo teórico da análise do discurso. ${ }^{5}$ Partindo do fato de que a cultura pode ser apreendida em "materialidades discursivas implicadas em rituais ideológicos, nos discursos filosóficos, em enunciados políticos, nas formas culturais e estéticas" (PÊCHEUX, [1983] 1990 , p. 49), pode-se inferir que ela é constituída de um conjunto de práticas diversificadas, desiguais e não homogêneas que fazem parte da memória de um corpo social, inscrevendo-se, por conseguinte, no interdiscurso e funcionando sob o efeito da ideologia, isto é, seus saberes e seus efeitos de sentido são por ela regulados.

Os efeitos de sentido que as práticas culturais produzem no âmbito do corpo social têm um funcionamento ideológico similar ao de uma formação discursiva. $\mathrm{O}$ sujeito da escrita pode com eles se identificar e tomá-los como transparentes e cristalizados. Nesse caso, essas práticas são naturalizadas e inscrevem-se na ordem da repetibilidade, e funcionam em rituais que produzem um efeito de evidência, decorrente da regulação dos sentidos que a repetição produz (INDURSKY, 2011, p. 71).
Mas, como afirma Carme Schons, na epígrafe desta seção, "a repetição requer interpretação e memória ao mesmo tempo" (2005, p. 152). Ou seja, quando uma prática cultural é mobilizada em uma prática de escrita, ela está sujeita à interpretação produzida a partir do lugar discursivo em que se inscreve o sujeito, que poderá vir a questioná-la e, mesmo, resistir-lhe. Ou seja, "não há ritual sem falha" e, por conseguinte, "o ritual pode quebrar-se no lapso ou no ato falho" ([1982] 1990, p. 17), como nos lembra Pêcheux. Quando isso ocorre, o efeito de evidência se opacifica, podendo mesmo instaurar-se a dúvida e a possibilidade de deslocar seu efeito de sentido. Por conseguinte, práticas culturais, tal como qualquer outro saber inscrito em formações discursivas, funcionam ao abrigo tanto da repetibilidade quanto da deriva dos sentidos. Podemos dizer, juntamente com De Nardi, que a cultura, ao revestir-se de uma dimensão político-histórico-social, traz a "possibilidade de ser dinâmica e crítica, de propor rupturas, de produzir outros dizeres" (DE NARDI, 2007, p. 63-64).

Porém, em qualquer dos dois casos (identificação ou questionamento/resistência), as práticas culturais, ao passarem pela interpretação e, posteriormente pela discursivização, tornam-se saberes culturais que se inscrevem em formações discursivas diversas das quais recebem sentido.

Assim sendo, saberes/práticas culturais não significam a priori. Necessitam passar pela interpretação e pela língua para fazerem sentido e, desse modo, 
inscreverem-se em uma prática discursiva da escrita, participando, assim, de sua determinação.

\section{Interpretação, memória e esquecimento na prática discursiva da escrita}

A escrita, lugar de interpretação,
se forma em espaço simbólico
em que a memória trabalha. (SCHONS, 2005)

Há ainda mais uma articulação teórica que vai fazer laço nessa reflexão sobre as determinações da prática discursiva da escrita. Trata-se da articulação entre memória e esquecimento. Courtine chamou a atenção sobre o jogo que se trava entre o lembrar e o esquecer, quando afirmou que: "Memória e esquecimento são indissociáveis na enunciação do político" ([1983] 1999, p. 22). A medida que passei a refletir teoricamente sobre a análise do discurso, ousei reescrever essa afirmação, entendendo que memória e esquecimento são indissociáveis de todo e qualquer discurso (INDURSKY, [1997] 2013). E, no presente artigo, convoco novamente essa articulação, por entender que memória e esquecimento estão fortemente presentes na prática discursiva da escrita de um sujeito.

Por essa razão, retomo a epígrafe que abre esta seção, assim, reescrevendo a afirmação de Schons: a prática da escrita, lugar de interpretação, se forma em espaço simbólico em que trabalham conjuntamente a memória e o esquecimento. Ou seja: o sujeito, em sua prática da escrita, retoma saberes, o que aponta para sua inscrição no interdiscurso e na ordem da repetibilidade. Mas, para escrever, o sujeito necessita esquecer que esses sentidos já estão postos. De modo que, ao retomá-los em sua escrita, o faz como se fossem seus. A prática da escrita, como se pode ver, põe em jogo, no mesmo movimento, a memória discursiva com os sentidos já lá inscritos, que são retomados e/ou rememorados, e o esquecimento, pois é preciso esquecer que os sentidos preexistem para poder dizer.

Mas não só. Voltemos a Pêcheux, mais uma vez:

A condição essencial da produção e interpretação de uma sequência não é passível de inscrição na esfera individual do sujeito psicológico. Ela reside de fato na existência de um corpo histórico de traços discursivos que constituem o espaço de memória da sequência ([1983] 2011, p. 145).

A concepção de memória de que trata a análise do discurso não é a memória subjetiva de um indivíduo, mas o espaço de memória próprio a uma sequência discursiva. Entretanto, isso não significa que tais sentidos estejam cristalizados. É ainda Pêcheux que explica:

[...] "reprodução" nunca significou "repetição do mesmo". [...] de tal forma que os processos de reprodução ideológicos também sejam abordados como local de resistência múltipla. Um local no qual surge o imprevisível contínuo porque cada ritual ideológico continuamente se depara com relações e atos falhos de todos os tipos, que interrompem a perpetuação das reproduções ([1982] 2011, p. 115, grifo do autor). 
O sujeito, em suas práticas discursivas de retomada, pode fazê-lo como uma rememoração ou pode fazê-lo para resistir aos sentidos que sua identificação ideológica lhe apresenta como evidentes e passar a questioná-los pelo viés da interpretação, que os lançará à deriva, interrompendo, assim, um ciclo de repetibilidade (INDURSKY, 2011) e fazendo trabalhar os sentidos sobre os sentidos. A repetibilidade, como nos ensina Pêcheux, não é apenas o lugar da reprodução dos sentidos, mas também o lugar de produção de resistências. $\mathrm{O}$ sujeito da escrita pode apropriar-se de sequências discursivas (fios discursivos) e, ao mesmo tempo, resistir a seus efeitos de sentido, dando origem, pelo viés da interpretação, a deslocamentos e derivas. $\mathrm{E}$, assim procedendo, esses novos efeitos de sentidos irão se inscrever no espaço de memória da sequência e materializar-se em sua prática discursiva da escrita.

É a memória discursiva, enquanto categoria de análise (INDURSKY, [1997] 2013), que permite acompanhar a trajetória de um enunciado, suas repetições bem como suas transformações. E certamente tanto as retomadas como seus deslizamentos subjazem às práticas discursivas do sujeito, dentre elas, a escrita de que aqui nos ocupamos. Ela constitui o lugar em que as "evidências" dos sentidos materializam o funcionamento da ideologia, tornando possível captar sua reprodução bem como seus deslocamentos. É a escrita que dá visibi- lidade ao modo como o sujeito é afetado pela ideologia.

Nesse passo, entretanto, é preciso observar que quem vai dar conta dessa trajetória dos saberes, de suas retomadas, apropriações, deslocamentos e derivas é o analista de discurso e não o sujeito em sua prática discursiva de escrita, para quem retomadas e deslizamentos são da ordem do inconsciente. E é exatamente porque o sujeito é atravessado pelo inconsciente que tais deslizamentos tornam-se possíveis, pois o sujeito não tem controle sobre eles, nem sobre sua relação com a ideologia. Essa é a questão que me fez interrogar a natureza da memória com que o sujeito trabalha sua escrita, ou seja, qual a relação da memória social com o modo com que o sujeito pratica a escrita.

Courtine ([1983] 1999, [1981] 2009), ao tratar da noção de formação discursiva e da memória discursiva que nela se constitui, considera que essa memória é lacunar, marcada por interditos, esquecimentos, recalcamentos.

No meu entendimento, o sujeito, por sua vez, ao identificar-se com uma formação discursiva, também passa por um processo semelhante: identifica-se de forma inconsciente e fortemente lacunar com os saberes da memória discursiva. Ou seja, sua identificação também é da ordem da incompletude. Essa memória não é individual nem plena. Esse modo lacunar do sujeito relacionar-se com essa memória é o que tenho chamado de memória fluida. ${ }^{6}$ 
Vejamos esse funcionamento mais de perto. $\mathrm{O}$ sujeito do discurso, em suas práticas discursivas, relaciona-se com uma memória social inscrita em práticas. Trata-se de uma memória que não é objeto de ensino nem, tampouco, está registrada em compêndios que possam ser consultados. Sobre essa memória não temos controle, pois ela é construída socialmente pelo viés de diferentes práticas sociais. Trata-se de uma memória fluida, esburacada, esgarçada, marcada pela vagueza. Essa memória inscreve-se em práticas sociais e é constituída a partir de fragmentos anônimos de discurso mais ou menos completos. Desse modo, o sujeito-autor, em sua prática discursiva da escrita, funciona sob o efeito desse tipo muito particular de memória, que se relaciona lacunarmente com a memória discursiva, com o interdiscurso, com as redes discursivas de memória, com os discursos em circulação. Ou seja: quanto mais lacunar e esgarçada for a memória fluida, mais a prática discursiva da escrita está sujeita ao equívoco e, mesmo, ao desconhecimento.

Se a prática discursiva da escrita é marcada pelo esquecimento e pelas lacunas da memória fluida, o sujeito em sua prática é suscetível de se desviar de sentidos com que se identifica, produzindo deslocamentos entre formações discursivas. Tais movimentos do sujeito abrem a possibilidade de mobilizar fios discursivos estranhos à formação discursiva que afeta o sujeito e incorporá-los a sua escrita, entrelaçando o memorável ao estranho, ao desconhecido, sob o fun- cionamento da articulação entre memória e esquecimento. Esses movimentos da memória fluida, na constituição da subjetividade do sujeito, precedem o trabalho da escrita, mas é a escrita que vai consolidar essa movimentação, dar-lhe materialidade e visibilidade.

Assim procedendo, o sujeito da escrita estará produzindo gestos de resistência, e é por meio deles que novos sentidos poderão ser produzidos e inscritos no espaço de memória das sequências discursivas. Portanto, a escrita, como prática social e política, é determinada por esse conjunto de relações complexas entre língua, história e interpretação, que, por sua vez, são mediadas por uma memória fluida.

Essas são as condições de produção da prática discursiva da escrita.

\section{Alinhavando algumas considerações (não) conclusivas}

Inicio essas considerações (não)conclusivas, comentando seu título: sei, desde já, que vou voltar a girar meu imaginário caleidoscópio em outras direções, pois à medida que escrevia este texto pensava outras tantas questões que se relacionam ao processo da escrita. Mas, agora, é hora de produzir um ponto final para este texto e, para isso, vou alinha- 
var algumas questões que foram sendo apresentadas ao longo deste artigo.

Em busca das determinações da prática discursiva da escrita, fui encontrando relações que, aqui, neste espaço de fechamento, vou chamar de formas de articulação.

A primeira dessas articulações e a mais evidente, dentre elas, porque já há muito tempo trabalhada no campo teórico da análise do discurso, é o ponto de encontro do interdiscurso com o intradiscurso (COURTINE, [1981] 2009; PÊCHEUX, [1975] 1988). Essa articulação é extremamente importante para refletir sobre a prática discursiva da escrita, porque é nesse ponto que se dá a passagem dos fios discursivos provenientes do interdiscurso e que serão tecidos pela língua e materializados na escrita. É nesse ponto de articulação que o sujeito da escrita apropria-se de saberes e sintagmatiza-os, promovendo, dessa forma, a atualização de uma memória (PÊCHEUX, [1983] 1990).

A segunda articulação examinada neste artigo foi a da língua com a ideologia. Essa articulação foi considerada sob cinco aspectos. Primeiro: é por meio da língua que os saberes provenientes da formação discursiva e do interdiscurso são sintagmatizados e materializados, ou seja, é por intermédio de uma sintaxe discursiva que tais saberes ganham materialidade na escrita, apontando direções de sentido. Segundo: a carpintaria linguístico-discursiva da língua vai permitir observar os diferentes modos com que os sujeitos se relacionam com os saberes que são historicamente determinados, e, dessa forma, essa superfície linguística pode se constituir em um observatório da ideologia. Terceiro: é pela língua que a interpretação do sujeito, que é ideológica, ganha materialidade para produzir sentido em sua escrita. Quarto: a língua é opaca e sujeita a falhas, e, em função disso, a escrita do sujeito pode provocar deslizamentos e deriva dos sentidos.

A terceira articulação trabalhada neste artigo é a da ideologia com a cultura. Os saberes culturais, que constituem a cultura de um corpo social, são da ordem da repetibilidade e da ressignificação. Por conseguinte, são afetados pela ideologia e à sua luz são interpretados.

A quarta articulação examinada estabelece-se entre memória e esquecimento. Para que haja escrita, o sujeito inscreve-se na discursividade. Ele necessita de uma memória prévia para poder dizer. Mas, paradoxalmente, para que a prática da escrita se constitua, a retomada de discursos e sentidos já-lá precisa ser esquecida, abrindo espaço, dessa forma, às retomadas (identificações), às reformulações (contraidentificações) e, também, às transformações (desidentificações). A prática da escrita enlaça inexoravelmente memória e esquecimento pelo viés de uma memória fluida.

É por meio desses entrecruzamentos tão diversificados que a prática discursiva da escrita se tece e se produz. Mas não é só isso que subjaz a essa prática. Passemos, então, às determinações propriamente ditas. 
Como vimos, pelas diferentes articulações que se atravessam e se materializam na escrita do sujeito, essa prática é tecida de discursos e saberes culturais e inscreve o sujeito no corpo social e na discursividade em circulação. Esse é o papel da rememoração nos processos de escrita. Por conseguinte, ela é uma prática determinada socialmente. E, também, por ser uma prática de sujeitos ideologicamente constituídos, ela carrega, em sua materialidade, os vestígios de sua determinação histórica. Portanto, a prática discursiva da escrita é politicamente determinada.

Com base no que precede, entendemos que o sujeito, em sua prática discursiva da escrita, passa por um conjunto de determinações que subjazem à sua prática da escrita. Essas determinações do sujeito podem ser desenhadas como segue.

$$
\begin{aligned}
& \text { Interpelação ideológica } \rightarrow \text { interpretação } \\
& \text { das discursividades e das práticas/ } \\
& \text { saberes culturais } \rightarrow \text { materialização } \\
& \text { pela língua } \rightarrow \text { escrita }
\end{aligned}
$$

Observando tais determinações do sujeito em sua prática discursiva e o modo como elas estão encadeadas, percebe-se que há uma ordem que não é aleatória e que é determinante do processo da escrita. Entendemos tratar-se de um processo de determinação do sujeito que, por sua vez, determina sua prática da escrita, ou seja, trata-se de um processo complexo que inicia no sujeito e se estende à sua prática discursiva da escrita, sobredeterminando-a.
Como podemos perceber, a prática discursiva da escrita é uma prática política e social, sobredeterminada pelo imbricamento entre ideologia, interpretação e a língua, que, como vimos no corpo deste artigo, é marcada pela opacidade, sujeita a falhas e equívocos. Assim, a escrita, tecida de discurso e materializada pela língua, sofre várias determinações antes de desaguar na textualização, que vai carregar em si as marcas de uma língua não fechada e sujeita a falhas. Uma escrita assim pensada é um espaço simbólico, resultante de encontros, desencontros e confrontos mediados pela memória e o esquecimento.

\section{Produzindo um efeito-fecho}

$\mathrm{E}$, assim, ao chegar ao término deste artigo, este efeito-fecho, na verdade, devolve-me ao início deste trabalho e para meu propósito. Escrever sobre a prática discursiva da escrita foi o modo de homenagear Carme e sua reflexão. De seus escritos, tomei a noção de escrita, para com Carme estabelecer um diálogo teórico, pois esse é um tema de que ela se ocupou em um artigo do qual me fiz acompanhar ao longo deste trabalho. Em um determinado ponto de seu artigo, a autora afirma que:

[...] o trabalho da escrita nem sempre se constrói em torno de sujeitos e espaços definidos e a ausência de um interlocutor remete a uma fronteira não localizável (2005, p. 139). 
No caso aqui presente, este artigo constrói-se com sujeitos definidos e tendo Carme como o interlocutor primeiro. Ela foi uma presença-ausente ao longo de minha escrita. Carme, que passou por nossas vidas e cuja escrita engajada e apaixonada se entrelaçou à de muitos de nós, e que neste artigo veio entrelaçar-se à minha. Carme que conduziu meus passos, levando-me a retomar meus textos e rascunhá-los novamente para, junto com ela, refletir sobre a prática discursiva da escrita.

\section{Les déterminations de la pratique discursive de l'écriture}

\section{Résumé}

Cet article propose la refléxion sur la pratique discursive de l'écriture à la lumière du dispositif théorique de l'analyse du discours, prenant en considération que l'écriture, dans ce domaine théorique, est la pratique d'un sujet traversé par l'inconscient et interpellé par l'idéologie, d'un côté et, de l'autre, elle se produit à partir de la reprise de savoirs inscrits dans l'interdiscours, par le travail discursif de la l'interpretation, la mémoire et l'oubli. Voilà l'encadrement qui établit les conditions pour définit et examiner les éléments qui déterminent cette pratique discursive.

Mots-clé: Déterminations historiques et sociales. Interprétation. Langue. Mémoire et oubli. Matérialité linguistique-discursive.

\section{Notas}

1 Efeito-início é uma noção formulada por Noeli Tejera Lisbôa em sua dissertação de mestrado $A$ pontuação do silêncio: uma análise discursiva da escritura de Clarice Lispector, defendida na Universidade Federal do Rio Grande do Sul, em 2008.

2 Em trabalho anterior, A escrita à luz da análise do discurso (2009), busquei opor escrita a escritura para abordar as duas faces de um mesmo trabalho discursivo que se materializa no texto. Embora escrita, aqui, não traga o mesmo enfoque teórico que lá assumia, tem, como ponto de contato, o fato de que em ambos os textos, escrita não trata de uma atividade empírica, tomada como ato concreto de escrever, mas de uma prática discursiva do sujeito interpelado pela ideologia.

3 Andriana Pozzani de la Vieille e Silva trabalhou sobre essa questão em sua dissertação de mestrado, Entretextualidade nas fronteiras do enunciável: um olhar sobre o processo discursivo de reformulação de livros, defendida na Universidade Federal do Rio Grande do Sul, em 2008.

4 A noção de efeito-fecho foi formulada por Solange Maria Leda Gallo em sua tese de doutorado intitulada Texto: como apreender esta matéria, defendida na Unicamp; publicada, posteriormente, em 2008, com o título Como o texto se produz: uma perspectiva discursiva.

5 Maria Cristina Leandro Ferreira reflete sobre o lugar da cultura no âmbito do dispositivo teórico da análise do discurso. Conferir: FERREIRA, Maria Cristina Leandro. O lugar do social e da cultura numa dimensão discursiva. In: INDURSKY, F., MITTMANN, S.; FERREIRA, M. C. L. (Org.). Memória e história na/da análise do discurso. Campinas: Mercado das Letras, 2011. p. 55-64.

6 A noção foi desenvolvida no texto $\mathrm{O}$ ciclo da autoria nas práticas discursivas do sujeito, a ser publicado em livro organizado por Filomena Elaine Assolini e publicado pela Pontes.

\section{Referências}

\begin{abstract}
ALTHUSSER, Louis. Aparelhos ideológicos de Estado. In: ZIZEK, Slavoj. Um mapa da ideologia. Rio de Janeiro: Contraponto, 1996. p. 105-142. (Originalmente publicado em 1970).

COURTINE, Jean-Jacques. Análise do discurso político. São Carlos: Edufscar, 2009.
\end{abstract}


Traduzido de: Analyse du discours politique. (Originalmente publicado em 1981).

. O chapéu de Clémentis: observações sobre a memória e o esquecimento na enunciação do discurso político. In: INDURSKY, Freda; FERREIRA, Maria Cristina Leandro (Org.). Os múltiplos territórios da análise do discurso. Porto Alegre: Sagra-Luzzatto, 1999. p. 15-22. (Originalmente publicado em 1983).

DE NARDI, Fabiele S. Um olhar discursivo sobre língua, cultura e identidade: Reflexões sobre o livro didático para o ensino de espanhol como língua estrangeira. Tese (Doutorado em Teorias do texto e do discurso) - Programa de Pós-Graduação em Letras, Universidade Federal do Rio Grande do Sul, Porto Alegre, 2007.

GADET, Françoise; PÊCHEUX, Michel. A língua inatingível: o discurso na história e na linguística. Campinas: Pontes, 2004. (Originalmente publicado em 1981).

GALLO, Solange. Como o texto se produz: uma perspectiva discursiva. Blumenau: Nova Letra, 2008. (Originalmente publicado em 1994).

INDURSKY, Freda. Da heterogeneidade do discurso à heterogeneidade do texto e suas implicações no processo de leitura. In: ERNST-PEREIRA, Aracy; FUNCK, Suzana B. (Org.). A leitura e a escrita como práticas discursivas. Pelotas: Educat, 2001. p. 27-42.

. A fala dos quartéis e as outras vozes. 2. ed. Campinas: Unicamp, 2013. (Originalmente publicado em 1997).

. A escrita à luz da análise do discurso. In: CORTINA, Arnaldo; NASSER, Sílvia Maria Gomes (Org.). Sujeito e linguagem. São Paulo: Cultura Acadêmica, 2009. p. 117-131.

A memória na cena do discurso. In: INDURSKY, Freda; MITTMANN, Solange; FERREIRA, Maria Cristina Leandro (Org.). Memória e história na / da análise do discurso. Campinas: Mercado de Letras, 2011. p. 67-89.

ORLANDI, Eni P. Interpretação: autoria, leitura e efeitos do trabalho simbólico. Petrópolis: Vozes, 1996.
2001.

Discurso e texto. Campinas: Pontes,

Discurso em análise: sujeito, sentido, ideologia. Campinas: Pontes, 2012.

PÊCHEUX, Michel. Delimitações, inversões, deslocamentos. Cadernos de Estudos Linguísticos, Campinas, n. 19, p. 7-24, jul./dez. 1990. (Originalmente publicado em 1982).

Discurso: estrutura ou acontecimento. Campinas: Pontes 1990. (Originalmente publicado em 1983).

Ideologia: aprisionamento ou campo paradoxal? In: ORLANDI, Eni P. (Org.). Análise de discurso: Michel Pêcheux. Campinas: Pontes, 2011. p. 107-119. (Originalmente publicado em 1982).

Leitura e memória: projeto de pesquisa. In: ORLANDI, Eni P. (Org.). Análise de discurso: Michel Pêcheux. Campinas: Pontes: 2011. p. 141-150. (Originalmente publicado em 1983).

Semântica e discurso. Campinas: Unicamp, 1988. (Originalmente publicado em 1975).

PÊCHEUX, Michel; FUCHS, Catherine. A propósito da análise automática do discurso: atualização e perspectivas. In: GADET, Françoise; HAK, Tony (Org.). Por uma análise automática do discurso: uma introdução à obra de Michel Foucault. Campinas: Unicamp, 1990. p. 163-252. (Originalmente publicado em 1975).

SCHONS, Carme Regina. Escrita, efeito de memória e produção de sentidos. In: SCHONS, Carme Regina; RÖSING, Tania M. K. (Org.). Questões de escrita. Passo Fundo: UPF Editora, 2005. p. 138-156.

. "Adoráveis" revolucionários: produção e circulação de práticas político-discursivas no Brasil da Primeira República. 2006. Tese (Doutorado em Estudos da Linguagem) - Programa de Pós-Graduação em Letras, Universidade Federal do Rio Grande do Sul, Porto Alegre, 2006. 